\title{
A combined linkage and regional association mapping validation and fine mapping of two major pleiotropic QTLs for seed weight and silique length in rapeseed (Brassica napus L.)
}

$\mathrm{Na} \mathrm{Li}{ }^{\dagger}$, Jiaqin Shi ${ }^{\dagger}$, Xinfa Wang, Guihua Liu and Hanzhong Wang*

\begin{abstract}
Background: Seed weight (SW) and silique length (SL) are important determinants of the yield potential in rapeseed (Brassica napus L.). However, the genetic basis of both traits is poorly understood. The main objectives of this study were to dissect the genetic basis of SW and SL in rapeseed through the preliminary mapping of quantitative trait locus (QTL) by linkage analysis and fine mapping of the target major QTL by regional association analysis.

Results: Preliminary linkage mapping identified thirteen and nine consensus QTLs for SW and SL, respectively. These QTLs explained $0.7-67.1 \%$ and 2.1-54.4\% of the phenotypic variance for SW and SL, respectively. Of these QTLS, three pairs of SW and SL QTLs were co-localized and integrated into three unique QTLs. In addition, the significance level and genetic effect of the three co-localized QTLs for both SW and SL showed great variation before and after the conditional analysis. Moreover, the allelic effects of the three QTLs for SW were highly consistent with those for SL. Two of the three co-localized QTLs, uq.A09-1 (mean $R^{2}=20.1 \%$ and $19.0 \%$ for SW and SL, respectively) and uq.A09-3 (mean $R^{2}=13.5 \%$ and 13.2\% for SW and $S L$, respectively), were detected in all four environments and showed the opposite additive-effect direction. These QTLs were validated and fine mapped (their confidence intervals were narrowed down from $5.3 \mathrm{cM}$ to $1 \mathrm{cM}$ for uq.A09-1 and $13.2 \mathrm{cM}$ to $2.5 \mathrm{cM}$ for uq.A09-3) by regional association analysis with a panel of 576 inbred lines, which has a relatively rapid linkage disequilibrium decay $(0.3 \mathrm{Mb})$ in the target QTL region.

Conclusions: A few QTLs with major effects and several QTLs with moderate effects might contribute to the natural variation of SW and SL in rapeseed. The meta-, conditional and allelic effect analyses suggested that pleiotropy, rather than tight linkage, was the genetic basis of the three pairs of co-localized of SW and SL QTLs. Regional association analysis was an effective and highly efficient strategy for the direct fine mapping of target major QTL identified by preliminary linkage mapping.
\end{abstract}

Keywords: Rapeseed (Brassica napus L.), Linkage mapping, Regional association mapping, Seed weight/size, Silique length, Fine mapping, Linkage disequilibrium, Pleiotropy

\section{Background}

Linkage and association analyses are two complementary strategies for the genetic dissection of complex quantitative traits. Compared with each other, linkage mapping has relatively high power and a low false positive rate, whereas association mapping has relatively high

\footnotetext{
* Correspondence: wanghz@oilcrops.cn

${ }^{+}$Equal contributors

Oil Crops Research Institute of the Chinese Academy of Agricultural Sciences, Key Laboratory of Biology and Genetic Improvement of Oil Crops, Ministry of Agriculture, Wuhan 430062, China
}

\section{Biomed Central}

(c) 2014 Li et al.; licensee BioMed Central Ltd. This is an Open Access article distributed under the terms of the Creative Commons Attribution License (http://creativecommons.org/licenses/by/2.0), which permits unrestricted use, distribution, and reproduction in any medium, provided the original work is properly credited. The Creative Commons Public Domain Dedication waiver (http://creativecommons.org/publicdomain/zero/1.0/) applies to the data made available in this article, unless otherwise stated. resolution [1,2]. Linkage mapping is the traditional approach for identifying quantitative trait locus (QTL). Association mapping (including genome-wide, candidate gene and regional association) was originally used in humans [3] and animals $[4,5]$ and has been introduced to plants [6] in recent years. Very recently, joint linkageassociation mapping strategies have been proposed to utilize each method $[7,8]$, including parallel mapping (independent linkage and LD analysis) [9-13] and integrated mapping (dataset analysis in combination), such as 
MAGIC (Multi-parent advanced generation inter-crosses) [14] and NAM (nested association mapping) [15].

Both the seed weight (SW) and silique length (SL) are important determinants of yield potential in rapeseed and are good targets for selection in breeding [16,17] due to their high heritability [18]. The correlation between SW and SL has been investigated by many studies, but the directions of the coefficients were not consistent [19-21]. In general, an increase in silique length may lead to an increase in the source of matter [22], which results in larger seeds. Both SW and SL are quantitatively inherited, which are controlled by multiple QTLs, mainly with additive effects [20,21,23]. Only linkage analysis has been used for mapping QTLs of SW and SL in rapeseed [20,21,24-29], and no association analysis studies have been reported until now.

In particular, neither of the QTLs for SW and SL has been fine mapped. Following preliminary linkage mapping, the classical/traditional fine mapping strategy is based on the recombinant individuals screened from a large-scale NIL (near isogenic lines)-segregating population, which requires several rounds of successive backcrossing and self-crossing (cost of at least two years) and the genotyping of thousands of individuals [30,31]. Thus, the traditional NIL-based fine mapping approach is timeconsuming and labor-intensive. As an alternative, because of its relatively high resolution, association mapping can be used for fine mapping. However, high-throughput genomewide association analysis is unnecessary and wasteful for fine mapping one particular QTL of interest. To overcome these limitations, we proposed a combined linkage and regional association mapping strategy, which conducted association mapping at the specific genomic region of the target QTL that was identified by the preliminary linkage mapping.

In the current study, we used regional association mapping to validate and fine map two major SW and SL QTLs on the A09 linkage group of rapeseed that were identified by the preliminary linkage mapping. In detail, the main objectives of this study were as follows: (1) preliminary mapping of the QTLs for SW and SL using linkage analysis; (2) validation and fine mapping of the target major QTLs using regional association analysis; and (3) determination of the genetic basis of the colocalization of SW and SL QTLs using meta-, conditional and allelic effect analyses.

\section{Results}

Linkage mapping of the QTLs for SW and SL Phenotypic variation of the parents and segregating populations across environments

The two parents, Zhongshuang11 and No. 73290, differed significantly for SL but not SW in all the investigated environments (Additional file 1: Table S1). Transgressive segregation was observed for all of the populations in all environments, indicating the presence of favorable alleles in both parents. Both the SW and SL of the segregating populations showed normal or near-normal distributions (Figure 1, Additional file 1: Table S1), suggesting a quantitative inheritance pattern suitable for QTL identification. Interestingly, $\mathrm{SW}_{\mathrm{m}}$ (main raceme thousand seed weight) was higher than $\mathrm{SW}_{\mathrm{b}}$ (raceme branch thousand seed weight) by approximately $10 \%$ for both the parents and all of the populations in all environments, which was in agreement with a previous report [32].

The analysis of variance indicated that the genotypic, environmental and genotype $\times$ environment effects were all extremely significant for both SW and SL (Additional file 1: Table S2). Both SW and SL showed very high and similar heritability $\left(h^{2}=0.89,0.88,0.90\right.$ and 0.91 for $\mathrm{SW}_{\mathrm{m}}, \mathrm{SW}_{\mathrm{b}}, \mathrm{SW}_{\mathrm{w}}$ (whole-plant thousand seed weight) and SL, respectively), which was generally consistent with previous studies [21,27,29].

As expected, highly positive correlations were observed between $\mathrm{SW}_{\mathrm{m}}, \mathrm{SW}_{\mathrm{b}}$ and $\mathrm{SW}_{\mathrm{w}}$ in each experiment (Additional file 1: Table S3). A positive correlation between SW and SL was observed with moderate coefficients in almost all of the experiments (Table 1).

\section{Genome-wide detection and meta-analysis of the QTLS}

A framework of the genetic linkage map containing 529 loci (Additional file 1: Table S4) was constructed, which covered a total of $1934 \mathrm{cM}$ of the B. napus genome and had an average distance of $3.7 \mathrm{cM}$ between adjacent loci. The segregation distortion of each locus was estimated by the goodness-of-fit test, and 110 loci (20.7\%) showed distorted segregation. The biased loci were distributed unevenly: most of them were located on A01, A04, A06, A08, A09, C04 and C08 linkage groups, and the loci biased to the same parent tended to cluster together, which is a common phenomenon in B. napus [21,26,33]. Genome-wide QTL analysis was performed for SW and SL separately.

A total of 51 SW identified QTLs (25 significant QTLs and 26 overlapping suggestive QTLs) were detected (Additional file 1: Table S5). Of these, 18, 16 and 17 could be detected for main raceme, raceme branch and wholeplant thousand seed weight, respectively. These identified QTLs explained $0.7-67.1 \%$ of the phenotypic variance (mean $R^{2}=12.4 \%$ ). The meta-analysis integrated 48 overlapping identified QTLs into 10 repeatable consensus QTLs on the A01, A03, A04, A07, A08, A09 and C02 linkage groups (Table 2). Of these, five repeatable consensus QTLs were integrated from different tissues in the same experiment (experiment-specific), and the remaining five were integrated from different experiments (experimentrepeatable). Of the five experiment-repeatable consensus QTLs, $c q S W . A 01-2$ and $c q S W . A 07$ were detected in two environments (mean $R^{2}=6.5 \%$ and $6.6 \%$, respectively), 


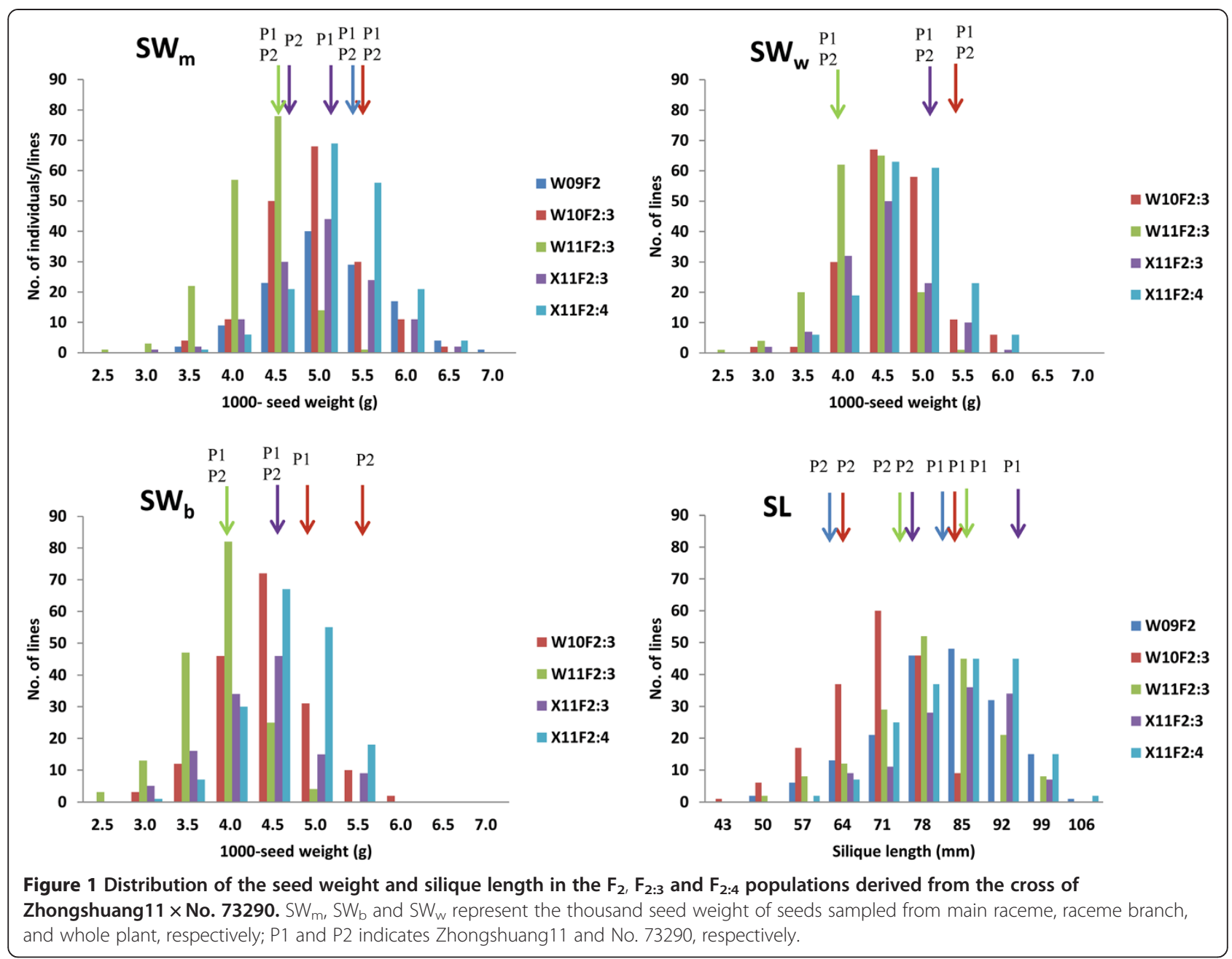

Table 1 Pearson's correlation coefficients of seed weight and silique length

\begin{tabular}{|c|c|c|c|c|c|c|}
\hline \multirow{2}{*}{$\begin{array}{l}\text { Experiments } \\
\text { code }\end{array}$} & \multirow[t]{2}{*}{ Trait } & \multicolumn{5}{|c|}{ SL } \\
\hline & & $\mathrm{W}_{09 F_{2}}$ & $\mathrm{~W} 10 \mathrm{~F}_{2: 3}$ & $\mathrm{~W} 11 \mathrm{~F}_{2: 3}$ & $\mathrm{X} 11 \mathrm{~F}_{2: 3}$ & $X 11 F_{2: 4}$ \\
\hline $\mathrm{W} \mathrm{FF}_{2}$ & $S W_{m}$ & $0.34^{* *}$ & $0.26^{* *}$ & $0.23^{*}$ & 0.19 & $0.30^{* *}$ \\
\hline \multirow[t]{3}{*}{${\mathrm{W} 10 \mathrm{~F}_{2: 3}}$} & $\mathrm{SW}_{\mathrm{m}}$ & $0.38^{* *}$ & $0.46^{* *}$ & $0.52^{* *}$ & $0.52^{* *}$ & $0.46^{* *}$ \\
\hline & $S W_{b}$ & $0.35^{* *}$ & $0.47^{* *}$ & $0.49^{* *}$ & $0.51^{* *}$ & $0.48^{* *}$ \\
\hline & $\mathrm{SW}_{\mathrm{w}}$ & $0.38^{* *}$ & $0.48^{* *}$ & $0.51^{* *}$ & $0.52^{* *}$ & $0.48^{* *}$ \\
\hline \multirow[t]{3}{*}{$\mathrm{W} 11 \mathrm{~F}_{2: 3}$} & $S W_{m}$ & $0.47^{* *}$ & $0.57^{* *}$ & $0.62^{* *}$ & $0.57^{* *}$ & $0.56^{* *}$ \\
\hline & $S W_{b}$ & $0.37^{* *}$ & $0.47^{* *}$ & $0.52^{* *}$ & $0.50^{* *}$ & $0.53^{* *}$ \\
\hline & $S W_{w}$ & $0.43^{* *}$ & $0.53^{* *}$ & $0.58^{* *}$ & $0.56^{* *}$ & $0.56^{* *}$ \\
\hline \multirow[t]{3}{*}{$\mathrm{X} 11 \mathrm{~F}_{2: 3}$} & $\mathrm{SW}_{\mathrm{m}}$ & $0.34^{* *}$ & $0.39^{* *}$ & $0.45^{* *}$ & $0.38^{* *}$ & $0.30^{* *}$ \\
\hline & $S W_{b}$ & $0.34^{* *}$ & $0.44^{* *}$ & $0.46^{* *}$ & $0.44^{* *}$ & $0.34^{* *}$ \\
\hline & $\mathrm{SW}_{\mathrm{w}}$ & $0.34^{* *}$ & $0.44^{* *}$ & $0.48^{* *}$ & $0.43^{* *}$ & $0.34^{* *}$ \\
\hline \multirow[t]{3}{*}{$\mathrm{X} 11 \mathrm{~F}_{2: 4}$} & $S W_{m}$ & $0.36^{* *}$ & $0.50^{* *}$ & $0.47^{* *}$ & $0.45^{* *}$ & $0.42^{* *}$ \\
\hline & $S W_{b}$ & $0.37^{* *}$ & $0.50^{* *}$ & $0.47^{* *}$ & $0.47^{* *}$ & $0.44^{* *}$ \\
\hline & $S W_{w}$ & $0.39^{* *}$ & $0.52^{* *}$ & $0.49^{* *}$ & $0.47^{* *}$ & $0.46^{* *}$ \\
\hline
\end{tabular}

$\overline{u * " \text { and }} "$ "**" represent the significant level of $\mathrm{P}=0.05$ and 0.01 , respectively.
cqSW.A08 and cqSW.A09-3 were detected in three environments (mean $R^{2}=5.3 \%$ and $13.5 \%$, respectively), and only one consensus QTL, cqSW.A09-1, was consistently detected in all four environments (mean $R^{2}=20.1 \%$ ).

A total of 18 SL identified QTLs (14 significant QTLs and four overlapping suggestive QTLs) were detected (Additional file 1: Table S5). These identified QTLs explained $2.1-54.4 \%$ of the phenotypic variance (mean $\left.R^{2}=12.4 \%\right)$. The meta-analysis integrated 12 overlapping identified QTLs into three repeatable consensus QTLs on the A09 and C02 linkage groups (Table 2). Of the three experiment-repeatable consensus QTLs, cqSL.A09-2 was detected in two environments (mean $\left.R^{2}=13.2 \%\right), c q S L . C 01$ was detected in three environments (mean $R^{2}=4.9 \%$ ), and only cqSL.A09-1 was detected in all four environments (mean $R^{2}=19.0 \%$ ).

The consensus QTLs for SW and SL were subjected to meta-analysis again, which resulted in 19 unique QTLs (Table 3). Of these, three unique QTLs, uq.A09-1, uq.A09-3 and uq.C02-1 were responsible for both SW and 
Table 2 Consensus QTLs for seed weight and silique length obtained by meta-analysis

\begin{tabular}{|c|c|c|c|c|c|c|c|}
\hline Consensus QTL & $\begin{array}{l}\text { Linkage } \\
\text { group }\end{array}$ & LOD & $R^{2}(\%)$ & $\begin{array}{l}\text { Peak } \\
\text { position }\end{array}$ & $\begin{array}{l}\text { Confidence interval } \\
\text { (2-LOD) }\end{array}$ & $\begin{array}{l}\text { Additive } \\
\text { effect }^{\mathrm{a}}\end{array}$ & Experiments code $(m, b, w)^{b}$ \\
\hline CQSW.A01-1 & $\mathrm{A} 01$ & $4.8-5.5$ & $1.7-1.8$ & 32.3 & $31.2-33.5$ & - & $\mathrm{W} 11 \mathrm{~F}_{2: 3}(\mathrm{~m}, \mathrm{w})$ \\
\hline CQSW.A01-2 & $\mathrm{A} 01$ & $2.7-3.5$ & $6.2-6.7$ & 43.9 & $41.6-46.2$ & - & 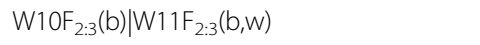 \\
\hline CQSW.A01-3 & $\mathrm{A} 01$ & $3.7-3.7$ & $0.8-1.7$ & 145.3 & $144.0-146.6$ & + & $\mathrm{W} 11 \mathrm{~F}_{2: 3}(\mathrm{~m}, \mathrm{~b})$ \\
\hline CaSW.A03-1 & A03 & 6.2 & 15.1 & 54.2 & $54.0-55.5$ & 0.42 & $\mathrm{WOSF}_{2}(\mathrm{~m})$ \\
\hline caSW.A03-2 & A03 & $2.6-3.0$ & $9.1-11.1$ & 79.8 & 78.7-80.9 & + & $\mathrm{W} 10 \mathrm{~F}_{2: 3}(\mathrm{~b}, \mathrm{w})$ \\
\hline CQSW.A04 & A04 & $3.8-4.0$ & $0.7-2.5$ & 76 & $75.5-76.5$ & + & $\mathrm{W} 11 \mathrm{~F}_{2: 3}(\mathrm{~m}, \mathrm{w})$ \\
\hline CQSW.A07 & A07 & $2.6-3.6$ & $4.0-11.7$ & 76.2 & 72.9-79.6 & \pm & $\mathrm{W} 10 \mathrm{~F}_{2: 3}(\mathrm{~b}) \mid \mathrm{W} 11 \mathrm{~F}_{2: 3}(\mathrm{~m}, \mathrm{~b}, \mathrm{~W})$ \\
\hline CqSW.A08 & A08 & $2.7-5.1$ & $1.1-13.9$ & 22 & $20.5-23.4$ & \pm & $\mathrm{W}_{09 F_{2}}(\mathrm{~m})\left|\mathrm{W} 10 \mathrm{~F}_{2: 3}(\mathrm{~b}, \mathrm{w})\right| \mathrm{W} 11 \mathrm{~F}_{2: 3}(\mathrm{~b}, \mathrm{w})$ \\
\hline CQSW.A09-1 & A09 & $2.7-10.0$ & $9.1-67.1$ & 42 & $40.9-43.1$ & - & $\begin{array}{l}\text { W09F }(m)\left|W 10 F_{2: 3}(m, b, w)\right| W 11 F_{2: 3}(m, b, w) \mid \\
X 11 F_{2: 3}(m) \mid X 11 F_{2: 4}(m, b, w)\end{array}$ \\
\hline CQSW.A09-2 & A09 & 9.3 & 13.4 & 86.3 & $84.3-88.2$ & 0.34 & $\mathrm{~W} 10 \mathrm{~F}_{2: 3}(\mathrm{~m})$ \\
\hline cQSW.A09-3 & A09 & $5.8-9.0$ & 7.2-26.9 & 109.4 & $106.5-112.3$ & + & $\mathrm{W} 10 \mathrm{~F}_{2: 3}(\mathrm{~m}, \mathrm{~b}, \mathrm{w})\left|\mathrm{W} 11 \mathrm{~F}_{2: 3}(\mathrm{~m}, \mathrm{w})\right| \mathrm{X} 11 \mathrm{~F}_{2: 4}(\mathrm{~m}, \mathrm{~b}, \mathrm{w})$ \\
\hline cqSW.CO2 & $\mathrm{CO2}$ & $3.6-4.4$ & 7.6-1.9 & 27.2 & $26.7-27.8$ & - & $\mathrm{W} 11 \mathrm{~F}_{2: 3}(\mathrm{~m}, \mathrm{w})$ \\
\hline caSW.C06 & C06 & 4.3 & 3.4 & 5 & $0-10.5$ & -0.19 & $\mathrm{X} 11 \mathrm{~F}_{2: 4}(\mathrm{~m})$ \\
\hline CQSL.A04-1 & $\mathrm{A} 04$ & 7.1 & 5.9 & 27.8 & $26.8-28.0$ & -8.61 & $\mathrm{X} 11 \mathrm{~F}_{2: 3}$ \\
\hline CQSL.A04-2 & A04 & 7.2 & 20.1 & 37.5 & $35.6-39.5$ & -4.77 & $\mathrm{X} 11 \mathrm{~F}_{2: 3}$ \\
\hline caSL.A06 & A06 & 6.2 & 9 & 23 & $17.3-25.6$ & 6.19 & $\mathrm{X} 11 \mathrm{~F}_{2: 4}$ \\
\hline caSL.A09-1 & A09 & $4.5-7.8$ & $7.8-544$ & 45.1 & $44.0-46.2$ & \pm & $\mathrm{W} 09 \mathrm{~F}_{2}\left|\mathrm{~W} 10 \mathrm{~F}_{2: 3}\right| \mathrm{W} 11 \mathrm{~F}_{2: 3}\left|\times 11 \mathrm{~F}_{2: 3}\right| \times 11 \mathrm{~F}_{2: 4}$ \\
\hline caSL.A09-2 & A09 & $10.0-15.4$ & $9.9-16.6$ & 109 & $102.5-115.6$ & + & $\mathrm{W}_{09 \mathrm{~F}_{2}} \mid \mathrm{W} 10 \mathrm{~F}_{2: 3}$ \\
\hline caSL.CO1 & C01 & $2.6-6.6$ & $2.1-9.7$ & 40.2 & $36.9-43.5$ & - & $\mathrm{W}_{09 F_{2}}\left|\mathrm{~W} 10 \mathrm{~F}_{2: 3}\right| \mathrm{W} 11 \mathrm{~F}_{2: 3}$ \\
\hline caSL.CO2-1 & $\mathrm{CO2}$ & 4.4 & 7.7 & 27.2 & $25.9-28.7$ & -9.8 & $\mathrm{~W}_{10 \mathrm{~F}_{2: 3}}$ \\
\hline caSL.CO2-2 & $\mathrm{CO2}$ & 4.1 & 5.1 & 35.9 & $31.6-42.2$ & -3.37 & $W 11 F_{2: 3}$ \\
\hline caSL.CO2-3 & $\mathrm{CO2}$ & 5.4 & 6.3 & 81.5 & $80.7-88.0$ & -4.58 & $\mathrm{X} 11 \mathrm{~F}_{2: 3}$ \\
\hline
\end{tabular}

a: "+", "-" and " \pm " indicate the direction of the additive effect.

$b$ : $m, b$ and $w$ represent the main raceme, raceme branch and whole-plant thousand seed weight, respectively.

SL. Specially, uq.A09-1 (flanking $5.3 \mathrm{cM}$ region) and uq. A09-3 (flanking $13.2 \mathrm{cM}$ region) were located on the A09 linkage group, with opposite additive-effect directions for both SW and SL.

To determine the genetic basis of three unique QTLs for both SW and SL (pleiotropy or tight linkage), conditional QTL analysis was performed (Table 4). When SW (represented by $\mathrm{SW}_{\mathrm{m}}$ ) was conditioned by $\mathrm{SL}\left(\mathrm{SW}_{\mathrm{m}} \mid \mathrm{SL}\right)$, none of the three loci (uq.A09-1, uq.A09-3, and uq.C02-1) remained significant for SW in all experiments; when SL was conditioned by SW $\left(\mathrm{SL} \mid S W_{\mathrm{m}}\right)$, these loci were not significant for SL in half of the experiments. These results strongly suggested that pleiotropy, rather than tight linkage was likely to be the genetic cause of the three unique QTLs for both SW and SL, and that SW was possibly contributed by SL for these loci.

\section{Regional association mapping}

SSR (Single Sequence Repeat) markers used for association mapping

The corresponding genomic regions of two major unique QTLs (uq.A09-1 and uq.A09-3) were identified by the alignment between the primer sequences of tightly linked SSR markers (BrSF6-2562 and BrSF0358) and the genomic sequences of $B$. napus (unpublished data) and $B$. rapa [34] due to the macro-colinearity between the A genomes of B. rapa and B. napus [35]. In total, 108 and 106 SSR markers (Additional file 1: Table S6) within the corresponding genomic regions of the two QTLs were newly synthesized. Of these, both six primer pairs were polymorphic between the two parents in the linkage mapping, and five and three SSR markers were selected for each locus for the association mapping. To screen more SSR markers for association mapping, the mini-core germplasms (Zhongshaung11, No. 73290, Tapitor and No. 91550) were used to screen the polymorphisms for the other SSR markers (including newly synthesized SSR markers and published SSR markers), and we obtained three and six polymorphic primer pairs for the two unique QTLs (Figure 2).

\section{Regional association mapping}

A large range of phenotypic variations was observed (Additional file 1: Table S1) for both SW ( 4-fold) and 
Table 3 Unique QTLs obtained from the meta-analysis of the consensus QTLs for each linkage group, separately

\begin{tabular}{lcccc}
\hline Unique QTL & $\begin{array}{c}\text { Linkage } \\
\text { group }\end{array}$ & $\begin{array}{c}\text { Peak } \\
\text { position }\end{array}$ & $\begin{array}{c}\text { Additive } \\
\text { effect }\end{array}$ & Type \\
\hline uq.A01-1 & A01 & 32.3 & - & SW-specific \\
uq.A01-2 & A01 & 43.9 & - & SW-specific \\
uq.A01-3 & A01 & 145.3 & + & SW-specific \\
uq.A03-1 & A03 & 54.2 & 0.42 & SW-specific \\
uq.A03-2 & A03 & 79.8 & + & SW-specific \\
uq.A04-1 & A04 & 27.8 & -8.61 & SL-specific \\
uq.A04-2 & A04 & 37.5 & -4.77 & SL-specific \\
uq.A04-3 & A04 & 76.0 & + & SW-specific \\
uq.A06 & A06 & 23.0 & 6.19 & SL-specific \\
uq.A07 & A07 & 76.2 & \pm & SW-specific \\
uq.A08 & A08 & 22.0 & \pm & SW-specific \\
uq.A09-1 & A09 & 41.8 & - & Pleiotropic \\
uq.A09-2 & A09 & 86.3 & 0.34 & SW-specific \\
uq.A09-3 & A09 & 109.3 & + & Pleiotropic \\
uq.C01 & C01 & 40.2 & - & SL-specific \\
uq.C02-1 & C02 & 27.2 & - & Pleiotropic \\
uq.C02-2 & C02 & 35.9 & -3.37 & SL-specific \\
uq.C02-3 & C02 & 81.5 & -4.58 & SL-specific \\
uq.C06 & C06 & 5.0 & -0.19 & SW-specific \\
\hline "+" "-" and "+" indicate the direction of the additive effect. &
\end{tabular}

SL ( 3-fold) in the association population. A significant weak correlation (0.47) was observed between SW and SL.

In this study, the $95^{\text {th }}$ percentile of the $R^{2}$ distribution for unlinked markers (markers from different

Table 4 Conditional analysis for the unique QTLs identified by linkage mapping

\begin{tabular}{|c|c|c|c|c|c|}
\hline \multirow{2}{*}{$\begin{array}{l}\text { Unique } \\
\text { QTL }\end{array}$} & \multirow{2}{*}{$\begin{array}{l}\text { Experiments } \\
\text { code }\end{array}$} & \multicolumn{4}{|c|}{ Additive effect $/ R^{2}(\%)$} \\
\hline & & $S W_{m}^{a}$ & $S W_{m} \mid S L^{b}$ & SL & $\mathrm{SL} \mid S W_{m}$ \\
\hline \multirow{5}{*}{ uq.A09-1 } & $\mathrm{W}_{09 F_{2}}$ & $-0.22 / 11.7$ & & $-6.13 / 54.4$ & $-5.58 / 30.2$ \\
\hline & $\mathrm{W} 10 \mathrm{~F}_{2: 3}$ & $-0.31 / 29.5$ & & $-3.64 / 15.2$ & \\
\hline & $\mathrm{W} 11 \mathrm{~F}_{2: 3}$ & $-0.18 / 16.9$ & & $-3.42 / 12.3$ & $-6.89 / 2.3$ \\
\hline & $\mathrm{X} 11 \mathrm{~F}_{2: 3}$ & $-0.17 / 15.1$ & & $-4.23 / 19.6$ & \\
\hline & $\mathrm{X} 11 \mathrm{~F}_{2: 4}$ & $-0.20 / 18.9$ & & $-3.18 / 11.7$ & \\
\hline \multirow{4}{*}{ uq.A09-3 } & $\mathrm{W} 0 \mathrm{~F}_{2}$ & & & $9.87 / 16.6$ & $7.71 / 15.1$ \\
\hline & $\mathrm{W} 10 \mathrm{~F}_{2: 3}$ & & & $3.52 / 4.8$ & $2.40 / 3.2$ \\
\hline & $\mathrm{W} 11 \mathrm{~F}_{2: 3}$ & $0.33 / 11.0$ & & & \\
\hline & $\mathrm{X} 11 \mathrm{~F}_{2: 4}$ & $0.30 / 7.9$ & & & \\
\hline \multirow{2}{*}{ uq. CO2-1 } & $\mathrm{W} 10 \mathrm{~F}_{2: 3}$ & & & $-9.80 / 7.7$ & \\
\hline & $\mathrm{W} 11 \mathrm{~F}_{2: 3}$ & $-0.92 / 1.9$ & & & \\
\hline
\end{tabular}

${ }^{a}$ : Only the main raceme 1000 seed weight dataset is used in each experiment for the conditional analysis.

$\mathrm{x} \mid \mathrm{y}^{\mathrm{b}}$ : Indicates trait $\mathrm{x}$ is conditioned by trait $\mathrm{y}$. chromosomes, Additional file 1: Table S7) determined the background level of $\mathrm{LD}\left(R^{2}<0.091\right)$. The extent of the $\mathrm{LD}$ decay was evaluated using linked markers (markers from the same chromosomes). The LD decay decreased within $1.40 \mathrm{Mb}$ over the whole genome and within $1.19 \mathrm{Mb}$ on the A09 linkage group. In particular, the extent of the LD decay for the target QTL region (major QTLs, discarding the markers involved in inversion, Figure 2) was $0.33 \mathrm{Mb}$ (Figure 3).

Considering the population structure (Additional file 1: Tables S7 and S8) and family relatedness (Additional file 1: Table S9) within the population, the association analysis was conducted with a mixed linear model (MLM) by TASSEL 3.0 using the 576-line sets and 17 QTL-linked SSR loci in the target region (Additional file 1: Table S6). Notably, six and eight of the 17 loci on the A09 linkage group (Table 5) with lower p-values (significant) were identified for SW and SL, respectively. Scanning of the association of SW and SL with the 17 loci on the A09 linkage group generally displayed two obvious peaks (Figure 4), which corresponded to the abovementioned two unique QTLs, uq.A09-1 and uq.A09-3. Within the first peak, the marker BrGMS0025 showed the strongest association for both SW (p=5.7E-13; $\left.R^{2}=14.6 \%\right)$ and SL ( $=8.4 \mathrm{E}-18$; $R^{2}=18.8 \%$ ) and was very near to BrSF6-2562, the nearest marker for uq.A09-1. Within the second peak, the marker BrSF6-1572 showed the strongest association signal for both $\mathrm{SW}\left(\mathrm{p}=1.2 \mathrm{E}-6 ; R^{2}=7.2 \%\right)$ and $\mathrm{SL}(\mathrm{p}=2.2 \mathrm{E}-13$; $R^{2}=13.8 \%$ ) and was near to BrSF0358, the nearest marker for $u q . A 09-3$.

To determine the resolution of this association study, the extent of the LD around the best associated SSR markers (BrGMS0025 and BrSF6-1572) was investigated. As expected, this region was divided into two LD blocks [36]. Eight and seven markers showed significant LD with BrGMS0025 and BrSF6-1572, respectively (Table 6, Figure 5). Of these, BnSF566-274 and BrSF6-2245 displayed significant LD with both BrGMS0025 and BrSF61572 , but their $R^{2}$ values were relatively lower than those of the other markers, which likely represented the overlapping region of the two LD blocks. The first LD block around the marker BrGMS0025 extended roughly from BrSF0353 (at $30.68 \mathrm{Mb}$ ) to BrSF6-2562 (at 31.19 Mb), indicating a resolution of approximately $1 \mathrm{cM}(0.51 \mathrm{Mb})$. Another LD block around the marker BrSF6-1572 extended roughly from BrSF6-1390 (at $29.02 \mathrm{Mb}$ ) to BrSF0358 (at $30.28 \mathrm{Mb}$ ), indicating a resolution of approximately $2.5 \mathrm{cM}(1.26 \mathrm{Mb})$.

\section{Conditional analysis}

To determine the genetic basis (pleiotropy or tight linkage) of the common association markers for SW and SL, conditional analysis was performed using two methods. The first method used the conditional phenotypic values, while the 


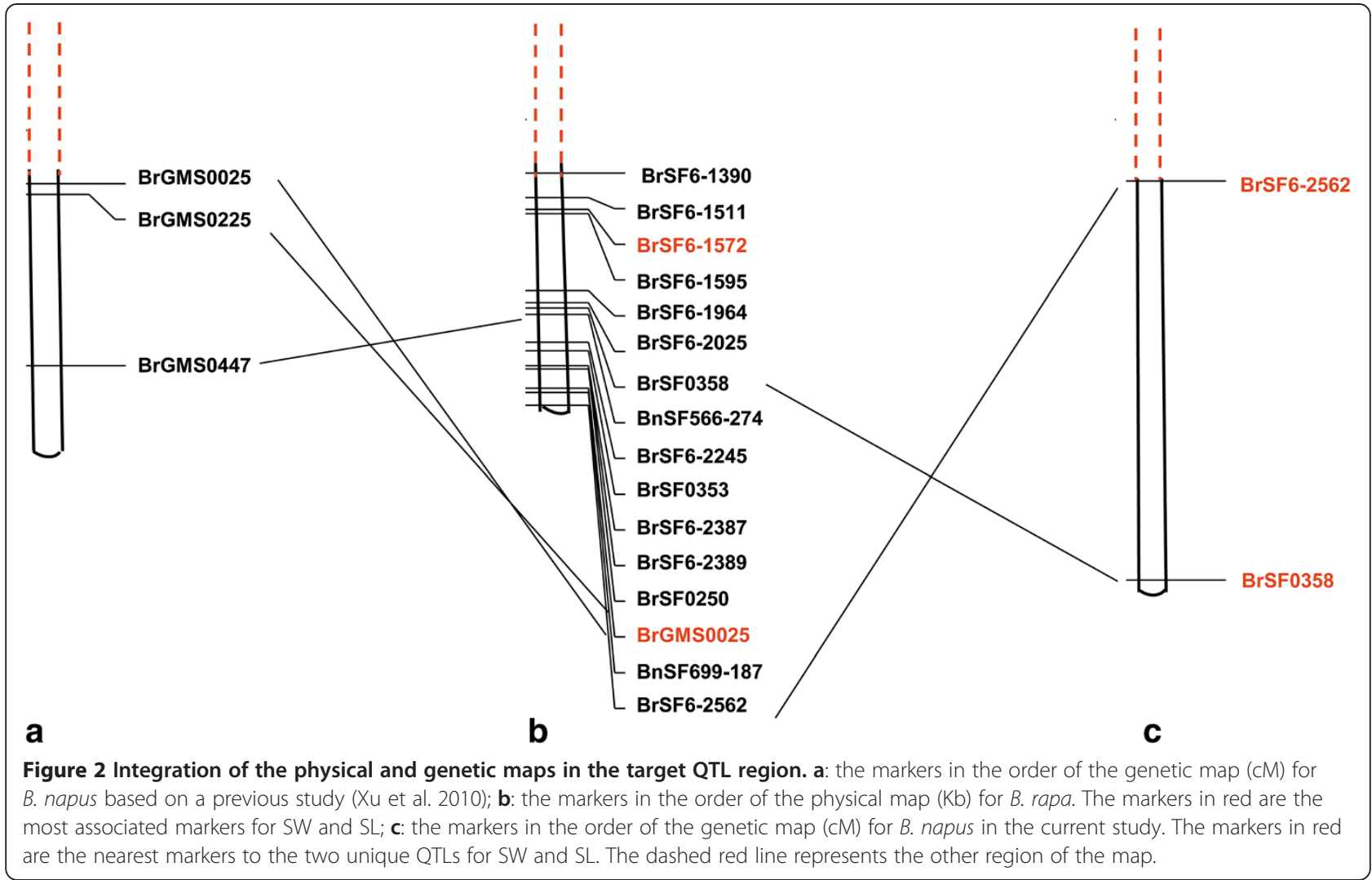

second method used one trait as a covariate for the other, to perform the association analysis. The results showed that the $\mathrm{p}$ value and $R^{2}$ of the association markers showed great variation before and after the conditional analysis using both methods (Table 5). Taking one of the peak signal markers, BrGMS0025, as an example, regardless of whether SW was conditioned by SL (SW|SL) or SL was conditioned by SW (SL|SW), both showed a strongly reduced effect (at least seven and eight orders of magnitude, respectively). This result indicated that the genetic basis of common association markers for SW and SL was likely to be pleiotropy rather than tight linkage.

\section{Allelic effects of the three pairs of co-localized SW and SL QTLs in the linkage and association populations}

The allelic effects of the co-localized SW and SL QTLs in the linkage and association populations were estimated using the phenotypic values of the different genotypes for the nearest marker (Table 7, Additional file 1: Table S10). The results showed that for all of the haplotypes of the three co-localized SW and SL QTLs (uq.A09-1, uq.A09-3 and uq.C02-1), their allelic effects for SW were highly accordant with those for SL in both the linkage and association populations. For example, the corresponding phenotypic values of the three major haplotypes (A, E and C) of the marker BrSF6-1572 (nearest to uq.A09-3) for SW and SL were $4.42 \mathrm{~g}$ and
$65.39 \mathrm{~mm}, 4.11 \mathrm{~g}$ and $62.51 \mathrm{~mm}$, and $3.97 \mathrm{~g}$ and $60.41 \mathrm{~mm}$, respectively. This finding increased the likelihood that pleiotropy rather than tight linkage was the underlying genetic basis for the three pairs of colocalized SW and SL QTLs.

\section{Discussion}

In the present study, we proposed a combined linkage and regional association mapping strategy to directly fine map target major QTLs. Using this strategy, the confidence intervals of the two major QTLs on the A09 linkage group were narrowed to approximately $1 / 5$ of those in the preliminary linkage mapping (basically, this strategy was used to achieve fine mapping). Our results suggested that this strategy is effective for direct fine mapping after preliminary linkage analysis. Compared with the traditional/classical NIL-based fine mapping approach [31], this strategy does not require the development and genotyping of a large-scale NIL segregating populations and is time- and labor-saving. In addition, our strategy can be applied to all plant species, especially those lacking high-density genome-wide genetic markers.

In previous genetic and QTL mapping studies, seed weight was usually measured separately from the main raceme $\left(\mathrm{SW}_{\mathrm{m}}\right)$, branch raceme $\left(\mathrm{SW}_{\mathrm{b}}\right)$ [32] and whole plant $\left(\mathrm{SW}_{\mathrm{w}}\right)[21,27,29]$. In the present work, $\mathrm{SW}_{\mathrm{m}}, \mathrm{SW}_{\mathrm{b}}$ and $\mathrm{SW}_{\mathrm{w}}$ were all measured for both the genetic and 

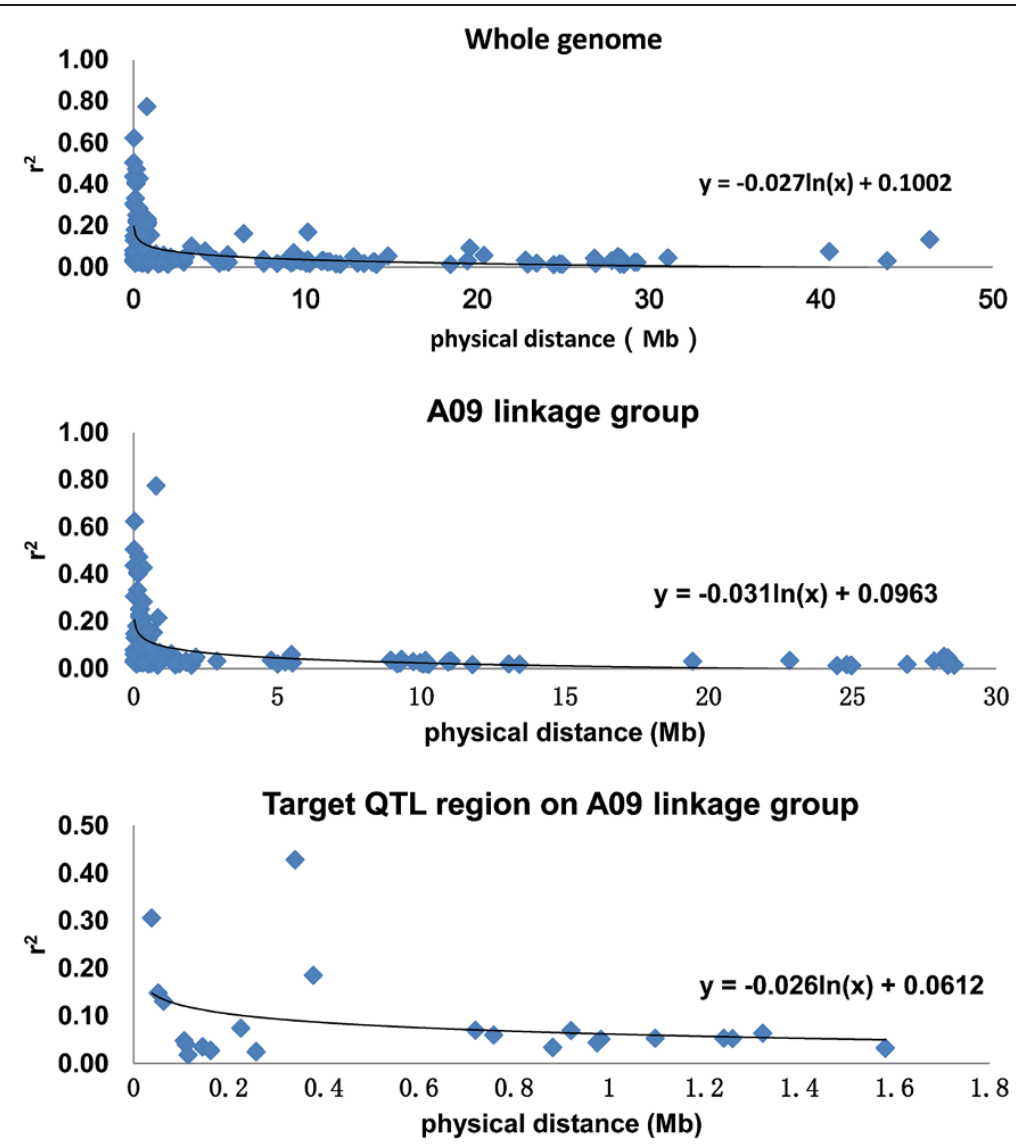

Figure 3 Scatterplot of the significant LD $\left(r^{2}\right)$ against physical distance (Mb) for the whole genome, A09 linkage group and target QTL region.

Table 5 Association and conditional analysis for seed weight and silique length

\begin{tabular}{|c|c|c|c|c|c|c|c|c|}
\hline \multirow{2}{*}{ Marker } & \multirow{2}{*}{ Linkage group } & \multirow{2}{*}{ Positions (Mb) } & \multicolumn{6}{|c|}{$\mathrm{p}$ value $/ \mathrm{R}^{2}(\%)$} \\
\hline & & & sW & SWSL1 ${ }^{\mathrm{a}}$ & SWSL2 ${ }^{\mathrm{b}}$ & SL & SLSW1 & SLSW2 \\
\hline BrSF6-1390 & A09 & 29.02 & & & & 7.7E-03/5.5 & & \\
\hline BrSF6-1511 & A09 & 29.25 & $2.0 \mathrm{E}-03 / 4.3$ & & & & & \\
\hline BrSF6-1572 & A09 & 29.36 & $1.2 \mathrm{E}-06 / 7.2$ & & & $2.2 \mathrm{E}-13 / 13.8$ & $2.5 \mathrm{E}-06 / 7.0$ & \\
\hline BrSF6-1595 & A09 & 29.4 & $8.2 \mathrm{E}-04 / 4.2$ & & & & & $2.2 \mathrm{E}-07 / 6.8$ \\
\hline BrSF6-2245 & A09 & 30.6 & & & & & & $1.6 \mathrm{E}-04 / 6.1$ \\
\hline BrSF6-1964 & A09 & 30.12 & 7.7E-06/8.6 & & & $3.3 \mathrm{E}-10 / 14.9$ & $1.0 \mathrm{E}-03 / 6.2$ & \\
\hline BrSF6-2025 & A09 & 30.23 & & & & $3.3 \mathrm{E}-06 / 8.8$ & $2.9 \mathrm{E}-04 / 7$ & $1.6 \mathrm{E}-04 / 6.1$ \\
\hline BrSF0358 & A09 & 30.28 & & & & $4.2 \mathrm{E}-03 / 3.9$ & & \\
\hline BrSF6-2387 & A09 & 30.82 & $1.4 \mathrm{E}-03 / 7.2$ & & & $2.3 \mathrm{E}-08 / 12.8$ & $5.0 \mathrm{E}-05 / 9.4$ & \\
\hline BrSF6-2389 & A09 & 30.82 & & & & & & $1.2 \mathrm{E}-05 / 8.6$ \\
\hline BrSF0250a & A09 & 30.85 & & & & $5.3 \mathrm{E}-03 / 2.7$ & & \\
\hline BrGMS0025 & A09 & 31.03 & $5.7 \mathrm{E}-13 / 14.6$ & $5.5 \mathrm{E}-03 / 3.2$ & $1.8 \mathrm{E}-06 / 6.3$ & $8.4 \mathrm{E}-18 / 18.8$ & $1.1 \mathrm{E}-07 / 8.5$ & $4.6 \mathrm{E}-10 / 9.5$ \\
\hline
\end{tabular}

$\mathrm{x} \mid \mathrm{y} 1^{\mathrm{a}}$ : Indicates that trait $\mathrm{x}$ is conditioned by trait $\mathrm{y}$ using the first conditional analysis method.

$\mathrm{x} \mid \mathrm{y} 2^{\mathrm{b}}$ : Indicates that trait $\mathrm{x}$ is conditioned by trait $\mathrm{y}$ using the second conditional analysis method. 


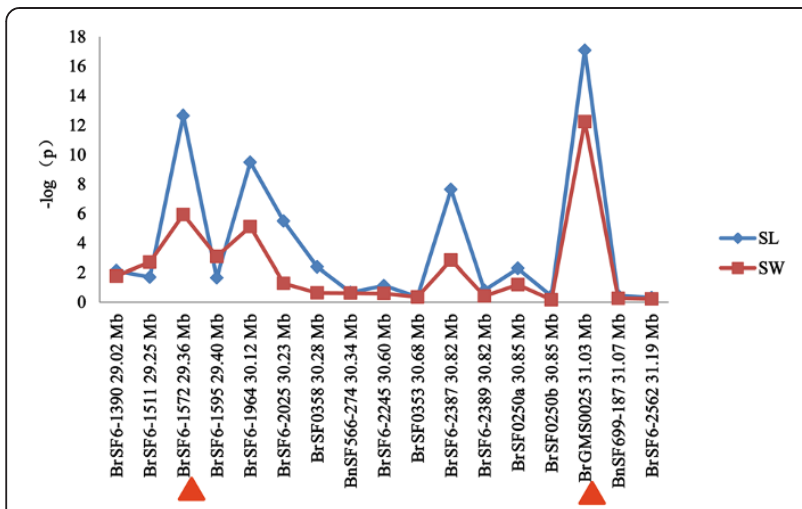

Figure 4 Scanning of the association (in - $\log 10[p]$ ) of seed weight and silique length with 17 marker loci on the A09 linkage group in rapeseed. The 17 marker loci are ordered on the horizontal axis according to their physical positions on the A09 linkage group of B. rapa. The red arrow points to peak signals.

QTL analyses. Strikingly, $\mathrm{SW}_{\mathrm{m}}$ showed an extremely high correlation with both $\mathrm{SW}_{\mathrm{b}}$ (mean $\mathrm{r}=0.93$ ) and $S W_{\mathrm{w}}$ (mean $\mathrm{r}=0.96$ ), and most of the QTLs identified for $\mathrm{SW}_{\mathrm{m}}, \mathrm{SW}_{\mathrm{b}}$ and $\mathrm{SW}_{\mathrm{w}}$ were consistent. However, $\mathrm{SW}_{\mathrm{m}}$ is more easily measured than $\mathrm{SW}_{\mathrm{b}}$ and $\mathrm{SW}_{\mathrm{w}}$. We therefore suggested the measurement of $\mathrm{SW}_{\mathrm{m}}$ rather than $\mathrm{SW}_{\mathrm{b}}$ and $\mathrm{SW}_{\mathrm{w}}$ in futher studies.

In the previous linkage QTL mapping studies, approximately 120 and 30 QTLs have been identified for SW [20,21,24,25,27-29,37] and SL [20,21,25,26], respectively, which were distributed on all and 16 of the 19 total linkage groups. Most of these QTLs showed relatively small effects, with only three major QTLs [27]: two on the A07

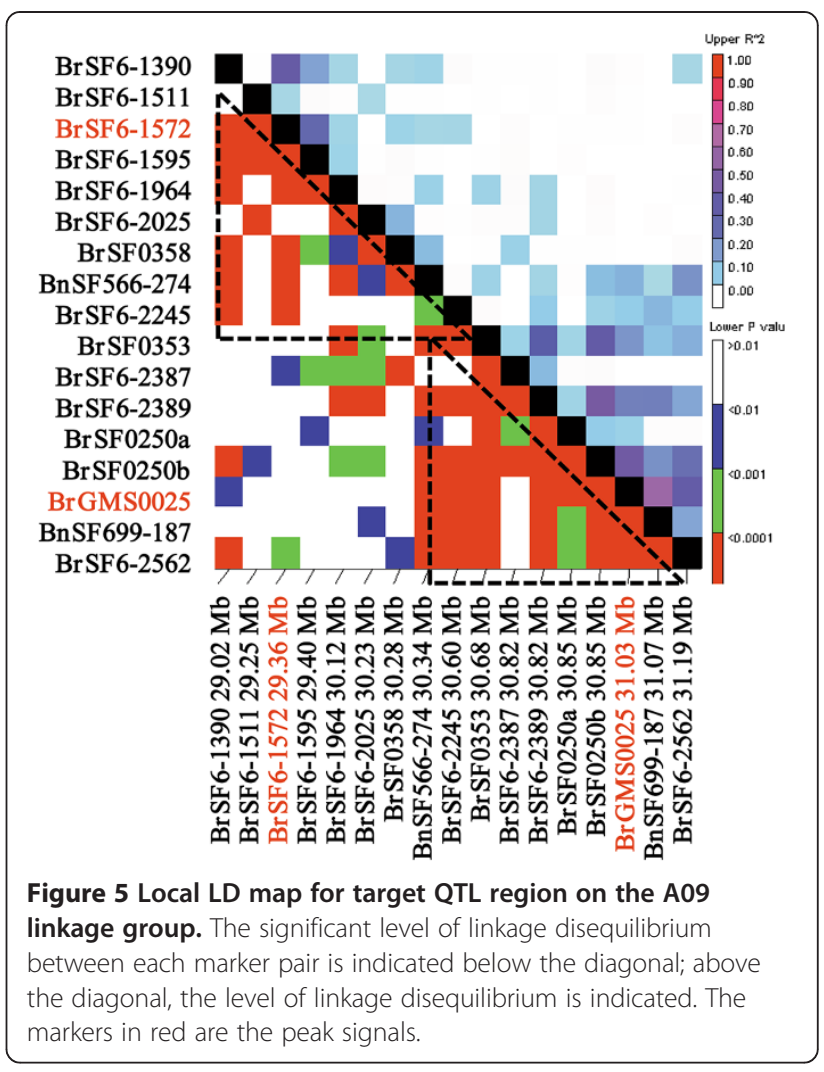

linkage group for SW and one on the A09 linkage group for both SW and SL. Of the $13 \mathrm{SW}$ and 9 SL consensus QTLs identified in the current linkage and association mapping studies, two (cqSW.A07 and cqSW.A09-3) and three (cqSL.A09-2, cqSL.C01 and cqSL.C02-3), respectively,

Table 6 Pairwise LD estimates between the peak signals, BrSF6-1572 and BrGMS0025, with the other markers at the level of $\mathbf{p} \leq \mathbf{0 . 0 0 1}$

\begin{tabular}{|c|c|c|c|c|c|c|}
\hline Peak signals & Position (Mb) & Other markers & Position (Mb) & Distance (Mb) & $r^{2}$ & $p$ value \\
\hline BrSF6-1572 & 29.36 & BrSF6-1390 & 29.02 & 0.34 & 0.43 & 0 \\
\hline BrSF6-1572 & 29.36 & BrSF6-1511 & 29.25 & 0.11 & 0.05 & $7.8 \mathrm{E}-07$ \\
\hline BrSF6-1572 & 29.36 & BrSF6-1595 & 29.40 & 0.04 & 0.31 & 0 \\
\hline BrSF6-1572 & 29.36 & BrSF6-1964 & 30.12 & 0.76 & 0.06 & 2.1E-06 \\
\hline BrSF6-1572 & 29.36 & BrSF0358 & 30.28 & 0.92 & 0.07 & 2.2E-07 \\
\hline BrSF6-1572 & 29.36 & BnSF566-274 & 30.34 & 0.98 & 0.05 & $3.1 \mathrm{E}-07$ \\
\hline BrSF6-1572 & 29.36 & BrSF6-2245 & 30.60 & 1.24 & 0.05 & 7.1E-07 \\
\hline BrGMSO025 & 31.03 & BnSF566-274 & 30.34 & 0.69 & 0.15 & 0 \\
\hline BrGMS0025 & 31.03 & BrSF6-2245 & 30.60 & 0.43 & 0.09 & 0 \\
\hline BrGMS0025 & 31.03 & BrSF0353 & 30.68 & 0.35 & 0.21 & 0 \\
\hline BrGMS0025 & 31.03 & BrSF6-2389 & 30.82 & 0.21 & 0.25 & 0 \\
\hline BrGMS0025 & 31.03 & BrSF0250a & 30.85 & 0.18 & 0.07 & 0 \\
\hline BrGMS0025 & 31.03 & BrSF0250b & 30.85 & 0.18 & 0.47 & 0 \\
\hline BrGMS0025 & 31.03 & BnSF699-187 & 31.07 & 0.04 & 0.62 & 0 \\
\hline BrGMSO025 & 31.03 & BrSF6-2562 & 31.19 & 0.16 & 0.41 & 0 \\
\hline
\end{tabular}


Table 7 Effect estimates of the three co-localized seed weight and silique length QTL in the linkage and association population

\begin{tabular}{|c|c|c|c|c|c|c|c|c|}
\hline Unique QTL & Population & Marker & Genotype $^{a}$ & Sample number & $S W_{m}^{d}$ & $\mathrm{SW}_{\mathrm{b}}$ & $\mathrm{SW}_{\mathrm{w}}$ & SL \\
\hline \multirow{6}{*}{ uq.A09-1 } & linkage mapping & BrSF6-2562 & P1 type & 58 & $4.63 \pm 0.56 a^{e}$ & $4.14 \pm 0.49 a$ & $4.35 \pm 0.52 a$ & $77.3 \pm 10.5 a$ \\
\hline & & & P2 type & 40 & $4.88 \pm 0.45 b$ & $4.33 \pm 0.43 b$ & $4.56 \pm 0.44 b$ & $79.8 \pm 7.1 \mathrm{a}$ \\
\hline & association mapping & BrGMS0025 & $\mathrm{D}(\mathrm{P} 1 / \mathrm{P} 2)^{\mathrm{b}}$ & 204 & $4.37 \pm 0.95 a$ & & & $66.3 \pm 13.5 a$ \\
\hline & & & C & 275 & $4.02 \pm 0.81 b$ & & & $60.9 \pm 10.9 b$ \\
\hline & & & $A^{c}$ & 6 & & & & \\
\hline & & & B & 17 & & & & \\
\hline \multirow{7}{*}{ uq.A09-3 } & linkage mapping & BrSF0358 & not $P 2$ type & 121 & $4.94 \pm 0.39 a$ & $4.40 \pm 0.37 a$ & $4.64 \pm 0.37 a$ & $82.6 \pm 6.4 a$ \\
\hline & & & P2 type & 63 & $4.52 \pm 0.50 \mathrm{~b}$ & $44.03 \pm 0.47 b$ & $4.23 \pm 0.48 b$ & $71.8 \pm 7.5 b$ \\
\hline & association mapping & BrSF6-1572 & A & 65 & $4.42 \pm 0.93 a$ & & & $65.4 \pm 13.0 \mathrm{a}$ \\
\hline & & & $\mathrm{E}(\mathrm{P} 1 / \mathrm{P} 2)$ & 248 & $4.11 \pm 0.85 b$ & & & $62.5 \pm 12.6 b$ \\
\hline & & & C & 171 & $3.97 \pm 0.80 b c$ & & & $60.4 \pm 9.2 \mathrm{ab}$ \\
\hline & & & D & 4 & & & & \\
\hline & & & B & 5 & & & & \\
\hline \multirow{2}{*}{ uq. CO2-1 } & linkage mapping & BoSF1827 & not $\mathrm{P} 2$ type & 114 & $4.80 \pm 0.45 a$ & $4.27 \pm 0.39 a$ & $4.49 \pm 0.41 a$ & $78.9 \pm 7.8 \mathrm{a}$ \\
\hline & & & P2 type & 45 & $4.85 \pm 0.43 a$ & $4.32 \pm 0.44 a$ & $4.57 \pm 0.45 a$ & $80.1 \pm 9.1 a$ \\
\hline
\end{tabular}

a: In linkage mapping, "P1 type" indicates marker phenotype that is the same as that of Zhongshuang11, "P2 type" indicates marker phenotype that is the same as that of No. 73290, "not P2 type " indicates marker phenotype that is not No. 73290 type; in association mapping, alleles are arranged in alphabetical order according to amplified fragment size. ${ }^{\mathrm{b}}$ : "P1/P2" indicates that Zhongshuang11 and No. 73290 have the same genotype in association population.

c: Rare alleles with an allele frequency of $<0.05$ are treated as missing data in the association population.

${ }^{d}: S_{m}, S W_{b}$ and $S_{W}$ are the mean values from all the experiments, and the details of each experimental analysis are shown in Additional file 1 : Table $S 10$.

e: Being followed by the same letter indicates no significant difference at the 0.05 probability level based on a Duncan-test.

have also been confirmed by the previous studies. The currently identified consensus QTLs, cqSW.A07, cqSL.C01 and cqSL.C02-3, likely corresponded with TSWA7a, sl11 and qSL.N12, respectively, which were detected in one of the previous studies and are located around the common markers BRMS036 [29], CB10369 [26] and CB10026 [20], respectively. The consensus QTLs, cqSW.A09-3 and cqSL.A09-2, were very close $(<1 \mathrm{Mb})$ to the $c q S W A 9$ and $c q S L A 9$ QTLs, respectively, which were identified in a previous study [21]. In addition, six SW QTLs have also been identified repeatedly around the markers CB10597 [21,28,37], MR119 [27,28,37], sR0282R [21,27,29], CB10536 [28,37], Na12E04 [28,37] and Ni4A07 [28,37] on A01, A05, A07, C01, C02 and C09 linkage groups, respectively, according to various previous studies. These "repeatable" QTLs found across the current and previous studies should be potential targets for marker-assisted selection. The four SW and two SL major QTLs found across these studies would be the important targets for map-based cloning. These results showed that both SW and SL were controlled by a large number of loci, mostly with small effects, which strongly suggested the complexity of the genetic basis of both traits.

The allotetraploid B. napus (AACC) was derived from chromosome doubling after the recent $(\sim 0.01$ million years ago) natural hybridization between its two diploid ancestors, B. rapa (AA) and Brassica oleracea (CC) [38]. The previous comparative genomics studies showed that although most of the homoeologous A genome linkage groups/chromosomes of B. rapa and B. napus showed co-linearity [35,39], some small-scale genomic changes also existed, including translocations [40], insertion/ deletions, inversions and rearrangements [35,41]. In the current study, a large fragment inversion was also revealed by the comparison between the $B$. napus linkage map and the $B$. rapa physical map of the QTL interval of uq.A09-1 and uq.A09-3 (Figure 2), which was also consistent with the previous comparative genomics studies [35]. These results explained the inconsistency between the large genetic distance $(30-50 \mathrm{cM})$ of uq.A09-1 and uq.A09-3 in $B$. napus and the close physical distance $(<1 \mathrm{Mb})$ in B. rapa.

The estimated genome-wide LD decay of the current $B$. napus association population was $1.4 \mathrm{Mb}$, which corresponds with approximately $2.8 \mathrm{cM}[42,43]$ and was slightly higher than those estimated $(0.5-2.0 \mathrm{cM})$ in previous studies on rapeseed [43-46]. The estimated LD decay on the A09 linkage group was $1.2 \mathrm{Mb}$, corresponding with $2.4 \mathrm{cM}$, which was very near that on the whole genome in our study and was slower than that (1 cM) estimated for the same linkage group in a previous study [44]. However, the LD decay of the target QTL interval $(0.3 \mathrm{Mb})$ was faster than those of the A09 linkage group and the whole genome. This observation suggested that the QTL region should be within a recombination hotspot, which was consistent with its location on 
the end of the A09 pseudo-chromosome and linkage group, most likely corresponding with the peri-telomere. This result also indicated that the target QTLs could be fine mapped through LD mapping with the current association population.

From the linkage and association analyses, a total of three co-localized SW and SL QTLs were identified, with the same additive-effect direction, which agreed with the significantly and moderately positive correlations in both populations. In fact, the co-localization of the SW and SL QTLs was also commonly observed in other previous studies $[20,21,27,29]$. However, the underlying genetic basis (pleiotropy or tight linkage) has not yet been studied intensively. Interestingly, the allelic effect, conditional and meta-analyses of the three colocalized QTLs all supported that pleiotropy rather than tight linkage was likely to be the underlying genetic basis in the current study. In addition, thousand seed weight of the $\mathrm{F}_{6}$ lines with extremely large $(\mathrm{SW}>6.0 \mathrm{~g})$ and small $(\mathrm{SW}<3.0 \mathrm{~g})$ seeds were in high accordance with the silique length of the corresponding lines $(r=0.87$, $\mathrm{p}<0.001$ ). Thus, the variations in SW might be primarily affected by those in the SL in the current linkage population, which is in accordance to the abovementioned conditional analysis for the three co-localized QTLs for both SW and SL. This finding is understandable because long siliques enable an increased photosynthesis area and assimilation, thereby providing the basis for the increase in the SW, and implicating maternal control of the underlying gene (s) [47-49]. Therefore, relevant genes within the genomic regions of the two major pleiotropic QTLs for SL rather than SW should be chosen as the preferential candidates. These results shed new light on the screening of candidate genes underlying complex quantitative traits: which one is the causal or the intermediate trait for complex trait?

\section{Conclusions}

In the present study, we proposed a regional association mapping strategy to directly fine map the target QTLs identified in preliminary linkage mapping. Compared with the traditional/classical NIL-based fine mapping strategies, our approach has many advantages, for example, it is time-saving, labor-saving and cost-effective. Using this strategy, the confidence intervals of the two major QTLs for both SW and SL on the A09 linkage group were successfully narrowed to a large extent, demonstrating the effectiveness of our strategy. Interestingly, the meta-, conditional and allelic effect analyses all suggest that pleiotropy, rather than tight linkage, was the genetic basis of the three unique QTLs for both SW and SL. Furthermore, the variations in SL are more likely to be the cause of the variation in SW, not vice versa. These results provide a solid basis for candidate gene screening and further gene cloning. In addition, several SW and/or SL QTLs identified by the current linkage mapping appeared to be "repeatable" in previous studies and could be the potential targets for marker-assisted selection in rapeseed breeding.

\section{Methods}

\section{Plant materials, field experiments and trait evaluation}

The linkage population included $184 \mathrm{~F}_{2}, \mathrm{~F}_{2: 3}$ and $\mathrm{F}_{2: 4}$ individuals/lines that were derived from two sequenced rapeseed cultivars, Zhongshuang11 (de novo sequencing, unpublished) and No. 73290 (re-sequencing, unpublished). The association population consisted of a panel of 576 rapeseed inbred lines (Additional file 1: Table S8), including both parental lines in linkage analysis.

Location-year combinations were treated as environments, and environment-population combinations were treated as experiments. The experiments were performed in two contrasting environments (semiwinter and spring rapeseed area). Details of the climate conditions during the growing season are described in Additional file 2: Figure $\mathrm{S} 1$. The $\mathrm{F}_{2}$ individuals were planted in Wuhan (Hubei province, semi-winter rapeseed area) from Oct. 2008 to May 2009 (code ${\mathrm{W} 09 \mathrm{~F}_{2}}_{2}$ ). The $\mathrm{F}_{2: 3}$ lines were planted in Wuhan from Oct. 2009 to May 2010 (code W10F $2: 3$ ) and Oct. 2010 to May 2011

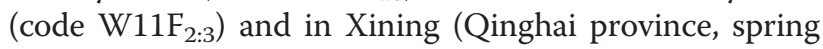

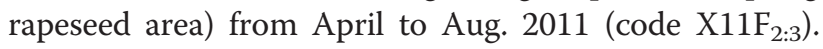
The $\mathrm{F}_{2: 4}$ lines were planted in Xining from April to

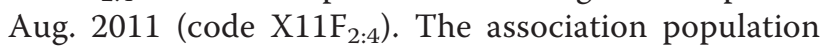
was planted in Wuhan from Oct. 2011 to May 2012 (code W12AP).

Both the linkage (including both parents) and association populations were arranged in a randomized complete block design with three replications (except $\mathrm{F}_{2}$ individuals). Each block contained two rows with 15 plants per row with spacing of $33.3 \times 16.7 \mathrm{~cm}$. The seeds were sown by hand, and the field management followed standard agriculture practice. In each block, 10 representative individuals from the middle of each row were harvested by hand at maturity.

For the linkage populations, the seeds from the main raceme and branch raceme were threshed separately. The SW was measured based on 1000 fully developed seeds. The main raceme thousand seed weight $\left(\mathrm{SW}_{\mathrm{m}}\right)$, raceme branch thousand seed weight $\left(\mathrm{SW}_{\mathrm{b}}\right)$ and whole-plant thousand seed weight $\left(\mathrm{SW}_{\mathrm{w}}\right)$ were each evaluated. For the $\mathrm{F}_{2}$ individuals, only $\mathrm{SW}_{\mathrm{m}}$ was measured. For the $\mathrm{F}_{2: 3}$ and $\mathrm{F}_{2: 4}$ lines, $\mathrm{SW}_{\mathrm{m}}, \mathrm{SW}_{\mathrm{b}}$ and $\mathrm{SW}_{\mathrm{w}}$ were measured. The SL was measured based on 10 well-developed siliques (not including the beak) from the main raceme. For the association population, $\mathrm{SW}_{\mathrm{m}}$ and SL were measured using the same method described above. 


\section{Statistical analysis}

The broad-sense heritability was calculated as $h^{2}=\sigma_{\mathrm{g}}^{2} /$ $\left(\sigma_{\mathrm{g}}^{2}+\sigma_{\mathrm{ge}}^{2} / \mathrm{n}+\sigma_{\mathrm{e}}^{2} / \mathrm{nr}\right)$, where $\sigma_{\mathrm{g}}^{2}$ was the genetic variance, $\sigma_{\mathrm{ge}}^{2}$ was the interaction variance of the genotype with environment, $\sigma_{\mathrm{e}}^{2}$ was the error variance, $\mathrm{n}$ was the number of environments and $\mathrm{r}$ was the number of replications. The estimation of $\sigma_{\mathrm{g}}^{2}, \sigma_{\mathrm{ge}}^{2}$ and $\sigma_{\mathrm{e}}^{2}$ were obtained from the SAS ANOVA procedure. Pearson's correlation coefficients were calculated using the SAS CORR procedure based on environment means.

\section{Polymorphism screening and map construction}

Genomic DNA was extracted from leaf tissues of the two parents (Zhongshuang11 and No. 73290) and its derived 184 $\mathrm{F}_{2}$ individuals. Three groups of markers from different sources were used for polymorphism screening between the two parents. The first group, mainly consisted of SSR and STS (sequence tagged site) markers, were selected from database of publish molecular markers in Brassica (http://www.brassica.info/resource/markers/ ssr-exchange.php) and published papers [33,35,50-60]. The second group, all consisted of SSR markers (prefixed "BoSF" and "BrSF"), were developed from three recently sequenced Brassica crops (B. rapa, B. oleracea and B. napus) by our lab [61]. The third group consisted of SNP (Single nucleotide polymorphism, prefixed "snap" and "ns") and InDel (Insertion/Deletion, prefixed "ni") markers, were also developed from the re-sequencing of No. 73290 by our lab (the primer sequences were provided in Additional file 1: Table S7). For markers detected at more than one polymorphism locus, a lowercase alphabetic letter was added to distinguish the loci. The PCR procedure, electrophoresis and silver staining were performed as described by Shi et al. [61].

The genetic linkage map was constructed using the JoinMap 4.0 software (http://www.kyazma.nl/index. $\mathrm{php} / \mathrm{mc}$.JoinMap) with the threshold for goodness-offit of $\leqq 5$, a recombination frequency of $<0.4$ and minimum logarithm of odds (LOD) score of 2.0. All genetic distances were expressed in centimorgans $(\mathrm{cM})$ as derived by the Kosambi function [62]. The segregation of each marker in the F2 population was analyzed by a chisquare test for "goodness-of-fit" to an expected segregation ratio $(\mathrm{P}<0.01)$.

\section{Linkage QTL mapping and meta-analysis}

The linkage mapping of QTLs was performed separately for SW and SL using the composite interval mapping program [63] of the WinQTL cartographer 2.5 software (http://statgen.ncsu.edu/qtlcart/WQTLCart.htm). A forward-backward stepwise regression following model 6 was performed to choose the co-factors (chosen with $\mathrm{P}_{\text {in }}=0.05$ and $\mathrm{P}_{\text {out }}=0.05$ ) before the QTL detection. The control marker numbers, window size and walking speed were set to $5,10 \mathrm{cM}$ and $1 \mathrm{cM}$, respectively. A default genetic distance of $5 \mathrm{cM}$ was used to define a QTL in a specific experiment. The experience-wise LOD threshold was determined by a permutation test of 1000 repetitions [64]. LOD scores corresponding to $\mathrm{P}=0.05$ were used to identify significant QTLs (3.62 - 4.94 for SW and $4.03-4.44$ for SL). To avoid missing QTLs with very small effects, a lower LOD value corresponding to $\mathrm{P} \leq 0.50$ was adopted in the presence of suggestive QTLs (2.43 - 3.70 for SW and 2.56 - 3.02 for SL). The overlapping suggestive QTLs and all significant QTLs were admitted $[27,65]$ and named as identified QTLs.

Meta-analysis was used to estimate the number and positions of the meta-QTLs underlying the QTLs of the same or related traits, which were repeatedly detected in different environments and located on the same chromosomal region [66]. The computation was conducted using BioMercator 2.1 software [67]. QTLs repeatedly identified for the same trait in different environments were first integrated into the consensus QTL, and then, the QTLs for different traits were further integrated into the unique QTL.

Each identified QTL was designated with the initial letter "q", followed by the name of the trait abbreviation (SW/SL) and linkage group. Each consensus QTL was designated with the initial letters "cq", followed by the name of the trait abbreviation and linkage group. Each unique QTL was designated with the initial letters "uq", followed by the name of the linkage group. Arabic numerals were added if more than one QTL was located on the same linkage group.

\section{Conditional QTL analysis}

To dissect the genetic basis (pleiotropy or tight linkage) of the co-localization of the SW and SL QTLs, conditional analysis was performed. The conditional phenotypic values y (T1/T2) were obtained by the mixed model approach for the conditional analysis of quantitative traits [68] using QGAStation 1.0 (http://ibi.zju.edu.cn/ software/qga/index.htm), where T1|T2 indicates that trait 1 is conditioned by trait 2 . Then, the conditional mapping of the QTLs was conducted according to the conditional phenotypic values using the same method as the unconditional QTLs mentioned above.

\section{Linkage disequilibrium (LD) evaluation}

The $R^{2}$ value of $\mathrm{LD}$ and the corresponding significance level (p value) were calculated using the TASSEL 3.0 standalone software (http://www.maizegenetics.net/index.php?option= com_content\&task=view\&id=89\&Itemid=119) with a permutation test of 1000 repetitions. Rare alleles with an allele frequency of $<0.05$ were treated as missing data [69]. The loci were considered to be in significant $\mathrm{LD}$ if $\mathrm{P} \leq 0.01$. The threshold of significant LD for linked loci was defined as 
the $95 \%$ quantile of the $R^{2}$ value among unlinked loci pairs $[44,70]$. Loci on the same linkage group were used to evaluate LD decay. To obtain a better visual description of the LD decay with distance, LD decay scatter plots of the $R^{2}$ values among the linked SSR pairs vs. the physical distance $(\mathrm{Mb})$ between those markers were generated. The LD decay was calculated as previously described [71].

\section{Regional association mapping}

Both the Q matrix and $\mathrm{K}$ matrix were calculated using allelic data from 93 SSR markers (Additional file 1: Table S7) with single banding patterns [72] that were evenly distributed across all 19 rapeseed chromosomes. The population structure ( $Q$ matrix) was determined using STRUCTURE v2.2 [73]. Then five independent simulations were processed for each k, ranging from 1 to 20 , with a 100,000 burn-in length and 100,000 iterations as previously reported [74]. The kinship matrix $\mathrm{K}$ was estimated using TASSEL $3.0[10,75,76]$.

We performed regional association mapping using 17 SSR loci within the target QTL genomic regions. The association analysis was calculated using the mixed linear model (MLM) method [76] incorporated into the TASSEL 3.0 software. The significant marker-trait associations were declared for $\mathrm{P} \leq 0.01$. The conditional analysis was also calculated by TASSEL 3.0 in the MLM model using one trait as a covariate for another trait.

\section{Additional files}

Additional file 1: Table S1. Descriptive statistics of seed weight $(\mathrm{g})$ and silique length $(\mathrm{mm})$ in the linkage and association populations. Table $\mathbf{S 2}$. ANOVA and broad-sense heritability $\left(h^{2}\right)$ of seed weight and silique length. Table S3. Correlation coefficients of seed weight in different tissues in the same experiment. Table S4. The constructed genetic linkage map for the $F_{2}$ population. Table S5. Identified QTLs for seed weight and silique length. Table S6. Molecular markers (within the target QTLs regions) used for association mapping. Table S7. Markers used for population structure analysis. Table S8. Genotype of the 17 SSR loci in association population. Table S9. Family relatedness for the association population. Table S10. Effect estimates of the three co-localized SW and SL QTLs in the linkage population.

Additional file 2: Figure S1. Details of the climate conditions, including monthly mean temperature, monthly maximum temperature, monthly minimum temperature, monthly sunshine and monthly rainfall during the growing season.

\footnotetext{
Abbreviations

SW: Seed weight; SWm: Main raceme thousand seed weight; SW branch thousand seed weight; $\mathrm{SW}_{\mathrm{w}}$ : Whole-plant thousand seed weight; SL: silique length; QTL: Quantitative trait locus; NIL: Near isogenic lines; MAGIC: Multi-parent advanced generation inter-crosses; NAM: Nested association mapping; LD: Linkage disequilibrium; GWA: Genome-wide association; SSR: Single sequence repeat; STS: Sequence tagged site; SNP: Single nucleotide polymorphism; InDel: Insertion /Deletion; cM: Centimorgans; MLM: Mixed linear model.
}

\section{Competing interests}

The authors declare no competing financial interests.

\section{Authors' contributions}

Conceived and designed the experiments: JQS, HZW; performed the experiments: NL, JQS; analyzed the data: NL, JQS; contributed reagents/ materials/analysis tools: HZW, GHL, XFW; wrote the manuscript: NL JQS. All authors read and approved the final manuscript.

\section{Acknowledgements}

This research was supported by the National Basic Research and Development Program (2011CB109305) of China, the National High Technology Research and Development Program (2012AA101107) of China, the Rapeseed Industry Technology System (CARS-13) and the Hubei Agricultural Science and Technology Innovation Center of China.

Received: 13 January 2014 Accepted: 22 April 2014

Published: 29 April 2014

\section{References}

1. Myles S, Peiffer J, Brown PJ, Ersoz ES, Zhang Z, Costich DE, Buckler ES: Association mapping: critical considerations shift from genotyping to experimental design. Plant Cell 2009, 21(8):2194-2202.

2. Khan MA, Korban SS: Association mapping in forest trees and fruit crops. J Exp Bot 2012, 63(11):4045-4060.

3. Lowe CE, Cooper JD, Brusko T, Walker NM, Smyth DJ, Bailey R, Bourget $K$, Plagnol V, Field S, Atkinson M, Clayton DG, Wicker LS, Todd JA: Large-scale genetic fine mapping and genotype-phenotype associations implicate polymorphism in the IL2RA region in type 1 diabetes. Nat Genet 2007, 39(9):1074-1082.

4. Meuwissen TH, Karlsen A, Lien S, Olsaker I, Goddard ME: Fine mapping of a quantitative trait locus for twinning rate using combined linkage and linkage disequilibrium mapping. Genetics 2002, 161(1):373-379.

5. Sahana G, Guldbrandtsen B, Thomsen B, Lund MS: Confirmation and fine-mapping of clinical mastitis and somatic cell score QTL in Nordic Holstein cattle. Anim Genet 2013, 40(6):620-626.

6. Huang X, Wei X, Sang T, Zhao Q, Feng Q, Zhao Y, Li C, Zhu C, Lu T, Zhang Z, Li M, Fan D, Guo Y, Wang A, Wang L, Deng L, Li W, Lu Y, Weng Q, Liu K, Huang T, Zhou T, Jing Y, Lin Z, Buckler ES, Qian Q, Zhang QF, Li J, Han B: Genome-wide association studies of 14 agronomic traits in rice landraces. Nat Genet 2010, 42(11):961-967.

7. Wu R, Zeng ZB: Joint linkage and linkage disequilibrium mapping in natural populations. Genetics 2001, 157(2):899-909.

8. Wu R, Ma CX, Casella G: Joint linkage and linkage disequilibrium mapping of quantitative trait loci in natural populations. Genetics 2002, 160(2):779-792.

9. Pagny G, Paulstephenraj PS, Poque S, Sicard O, Cosson P, Eyquard JP, Caballero M, Chague A, Gourdon G, Negrel L, Candresse T, Mariette S, Decroocq V: Family-based linkage and association mapping reveals novel genes affecting Plum pox virus infection in Arabidopsis thaliana. New Phytol 2012, 196(3):873-886.

10. Lu Y, Zhang S, Shah T, Xie C, Hao Z, Li X, Farkhari M, Ribaut JM, Cao M, Rong T, Xu Y: Joint linkage-linkage disequilibrium mapping is a powerful approach to detecting quantitative trait loci underlying drought tolerance in maize. Proc Natl Acad Sci U S A 2010, 107(45):19585-19590.

11. Cadic E, Coque M, Vear F, Grezes-Besset B, Pauquet J, Piquemal J, Lippi Y, Blanchard P, Romestant M, Pouilly N, Rengel D, Gouzy J, Langlade N, Mangin B, Vincourt P: Combined linkage and association mapping of flowering time in Sunflower (Helianthus annuus L.). Theor Appl Genet 2013, 126(5):1337-1356.

12. Famoso AN, Zhao K, Clark RT, Tung CW, Wright MH, Bustamante $C$, Kochian LV, McCouch SR: Genetic architecture of aluminum tolerance in rice (Oryza sativa) determined through genome-wide association analysis and QTL mapping. PLoS Genet 2011, 7(8):e1002221.

13. Korir PC, Zhang J, Wu K, Zhao T, Gai J: Association mapping combined with linkage analysis for aluminum tolerance among soybean cultivars released in Yellow and Changjiang River Valleys in China. Theor Appl Genet 2013, 126(6):1659-1675.

14. Kover PX, Valdar W, Trakalo J, Scarcelli N, Ehrenreich IM, Purugganan MD, Durrant C, Mott R: A Multiparent Advanced Generation Inter-Cross to fine-map quantitative traits in Arabidopsis thaliana. PLoS Genet 2009, 5(7):e1000551. 
15. McMullen MD, Kresovich S, Villeda HS, Bradbury P, Li H, Sun Q, Flint-Garcia S, Thornsberry J, Acharya C, Bottoms C, Brown P, Browne C, Eller M, Guill K, Harjes C, Kroon D, Lepak N, Mitchell SE, Peterson B, Pressoir G, Romero S, Oropeza Rosas M, Salvo S, Yates H, Hanson M, Jones E, Smith S, Glaubitz JC, Goodman M, Ware D, et al: Genetic properties of the maize nested association mapping population. Science 2009, 325(5941):737-740.

16. Ali N, Javidfar F, Elmira JY, Mirza MY: Relationship among yield components and selection criteria for yield improvement in winter rapeseed (Brassica napus L.). Pakistan J Bot 2003, 35(2):167-174.

17. Samizadeh H, Samadi BY, Behamta MR, Taleii A, Stringam GR: Study of pod length trait in doubled haploid Brassica napus population by molecular markers. J Agric Sci Technol 2007, 9:129-136.

18. Zhang G, Zhou W: Genetic analyses of agronomic and seed quality traits of synthetic oilseed Brassica napus produced from interspecific hybridization of B. campestris and B. oleracea. J Genet 2006, 85(1):45-51.

19. Aytac Z, Kinaci G: Genetic variability and association studies of some quantitative characters in winter rapeseed (Brassica napus L.). Afr J Biotechnol 2009, 8(15):3547-3554.

20. Zhang L, Yang G, Liu P, Hong D, Li S, He Q: Genetic and correlation analysis of silique-traits in Brassica napus L. by quantitative trait locus mapping. Theor App/ Genet 2011, 122(1):21-31.

21. Yang P, Shu C, Chen L, XU J, Wu J, Liu K: Identification of a major QTL for silique length and seed weight in oilseed rape (Brassica napus L.). Theor Appl Genet 2012, 125(2):285-296.

22. Chay $P$, Thurling N: Identification of genes controlling pod length in spring rapeseed, Brassica napus L., and their utilization for yield improvement. Plant Breed 1989, 103(1):54-62.

23. Li M, Gu J: Analysis of the gene effects for agronomic traits in rapeseed. Acta Agric Zhejiangensis 1992, 4:149-153.

24. Quijada PA, Udall JA, Lambert B, Osborn TC: Quantitative trait analysis of seed yield and other complex traits in hybrid spring rapeseed (Brassica napus L.): 1. Identification of genomic regions from winter germplasm. Theor Appl Genet 2006, 113(3):549-561.

25. Udall JA, Quijada PA, Lambert B, Osborn TC: Quantitative trait analysis of seed yield and other complex traits in hybrid spring rapeseed (Brassica napus L.): 2. Identification of alleles from unadapted germplasm. Theor Appl Genet 2006, 113(4):597-609.

26. Chen W, Zhang Y, Liu X, Chen B, Tu J, Tingdong F: Detection of QTL for six yield-related traits in oilseed rape (Brassica napus) using DH and immortalized F2 populations. Theor Appl Genet 2007, 115(6):849-858

27. Shi J, Li R, Qiu D, Jiang C, Long Y, Morgan C, Bancroft I, Zhao J, Meng J: Unraveling the complex trait of crop yield with quantitative trait loci mapping in Brassica napus. Genetics 2009, 182(3):851-861.

28. Basunanda P, Radoev M, Ecke W, Friedt W, Becker HC, Snowdon RJ: Comparative mapping of quantitative trait loci involved in heterosis for seedling and yield traits in oilseed rape (Brassica napus L.). Theor Appl Genet 2010, 120(2):271-281.

29. Fan C, Cai G, Qin J, Li Q, Yang M, Wu J, Fu T, Liu K, Zhou Y: Mapping of quantitative trait loci and development of allele-specific markers for seed weight in Brassica napus. Theor App/ Genet 2010, 121(7):1289-1301.

30. Hao W, Lin HX: Toward understanding genetic mechanisms of complex traits in rice. J Genet Genomics 2010, 37(10):653-666.

31. Salvi S, Tuberosa R: To clone or not to clone plant QTLs: present and future challenges. Trends Plant Sci 2005, 10(6):297-304.

32. Zhang SJ, Liao X, Zhang CL, Xu HJ: Influences of plant density on the seed yield and oil content of winter oilseed rape (Brassica napus L.). Ind Crop Prod 2012, 40:27-32.

33. Li HT, Chen X, Yang Y, Xu JS, Gu JX, Fu J, Qian XJ, Zhang SC, Wu JS, Liu KD: Development and genetic mapping of microsatellite markers from whole genome shotgun sequences in Brassica oleracea. Mol Breeding 2011, 28(4):585-596.

34. Wang $X$, Wang $H$, Wang J, Sun R, Wu J, Liu S, Bai Y, Mun JH, Bancroft I, Cheng F, Huang S, Li X, Hua W, Freeling M, Pires JC, Paterson AH, Chalhoub B, Wang B, Hayward A, Sharpe AG, Park BS, Weisshaar B, Liu B, Li B, Tong C, Song C, Duran C, Peng C, Geng C, Koh C, et al: The genome of the mesopolyploid crop species Brassica rapa. Nat Genet 2011, 43(10):1035-1039.

35. Xu J, Qian X, Wang X, Li R, Cheng X, Yang Y, Fu J, Zhang S, King GJ, Wu J, Liu K: Construction of an integrated genetic linkage map for the $A$ genome of Brassica napus using SSR markers derived from sequenced BACs in B. rapa. BMC Genomics 2010, 11:594.
36. Stich B, Melchinger AE, Frisch M, Maurer HP, Heckenberger M, Reif JC: Linkage disequilibrium in European elite maize germplasm investigated with SSRs. Theor Appl Genet 2005, 111(4):723-730.

37. Radoev M, Becker HC, Ecke W: Genetic analysis of heterosis for yield and yield components in rapeseed (Brassica napus L.) by quantitative trait locus mapping. Genetics 2008, 179(3):1547-1558.

38. U N: Genome analysis in Brassica with special reference to the experimental formation of $B$. napus and peculiar mode of fertilization. Japan J Bot 1935, 7:389-452.

39. Wang J, Lydiate DJ, Parkin IA, Falentin C, Delourme R, Carion PW, King GJ: Integration of linkage maps for the Amphidiploid Brassica napus and comparative mapping with Arabidopsis and Brassica rapa. BMC Genomics 2011, 12:101.

40. Osborn TC, Butrulle DV, Sharpe AG, Pickering KJ, Parkin IA, Parker JS, Lydiate DJ: Detection and effects of a homeologous reciprocal transposition in Brassica napus. Genetics 2003, 165(3):1569-1577.

41. Udall JA, Quijada PA, Osborn TC: Detection of chromosomal rearrangements derived from homologous recombination in four mapping populations of Brassica napus L. Genetics 2005, 169(2):967-979.

42. Suwabe K, Tsukazaki H, Iketani H, Hatakeyama K, Kondo M, Fujimura M, Nunome T, Fukuoka H, Hirai M, Matsumoto S: Simple sequence repeatbased comparative genomics between Brassica rapa and Arabidopsis thaliana: the genetic origin of clubroot resistance. Genetics 2006, 173(1):309-319.

43. Ecke W, Clemens R, Honsdorf N, Becker HC: Extent and structure of linkage disequilibrium in canola quality winter rapeseed (Brassica napus L.). Theor App/ Genet 2010, 120(5):921-931.

44. Wang XX, Zhang CY, Li ப, Fritsche S, Endrigkeit J, Zhang WY, Long Y, Jung C, Meng JL: Unraveling the genetic basis of seed tocopherol content and composition in rapeseed (Brassica napus L.). Plos one 2012, 7(11):e50038.

45. Xiao Y, Cai D, Yang W, Ye W, Younas M, Wu J, Liu K: Genetic structure and linkage disequilibrium pattern of a rapeseed (Brassica napus L.) association mapping panel revealed by microsatellites. Theor Appl Genet 2012, 125(3):437-447.

46. Delourme R, Falentin C, Fomeju BF, Boillot M, Lassalle G, Andre I, Duarte J, Gauthier V, Lucante N, Marty A, Pauchon M, Pichon JP, Ribiere N, Trotoux G, Blanchard P, Riviere N, Martinant JP, Pauquet J: High-density SNP-based genetic map development and linkage disequilibrium assessment in Brassica napus L. BMC Genomics 2013, 14:120.

47. Leng SH, Zhu GR, Deng XL: Studies on the sources of the dry matter in the seed of rapeseed. Acta Agronmica Sinica 1992, 18(4):251-256.

48. Leng SH, Tang Y, Li QY, Zuo QS, Yang P: Studies on source and sink of rapeseed I. Regulation of pod size on source and sink in rapeseed after flowering. Chinese J Oil Crop Sci 2006, 27(3):37-40.

49. Hua W, Li RJ, Zhan GM, Liu J, Li J, Wang XF, Liu GH, Wang HZ: Maternal control of seed oil content in Brassica napus: the role of silique wall photosynthesis. Plant J 2012, 69(3):432-444

50. Lagercrantz $U$, Ellegren $H$, Andersson $L$ : The abundance of various polymorphic microsatellite motifs differs between plants and vertebrates. Nucleic Acids Res 1993, 21(5):1111-1115.

51. Kresovich S, Szewc-McFadden A, Bliek S, McFerson J: Abundance and characterization of simple-sequence repeats (SSRs) isolated from a size-fractionated genomic library of Brassica napus L. (rapeseed). Theor App/ Genet 1995, 91(2):206-211

52. Szewc-McFadden AK, Kresovich S, Bliek SM, Mitchell SE, McFerson JR: Identification of polymorphic, conserved simple sequence repeats (SSRs) in cultivated Brassica species. Theor Appl Genet 1996, 93(4):534-538.

53. Uzunova Ml, Ecke W: Abundance, polymorphism and genetic mapping of microsatellites in oilseed rape (Brassica napus L.). Plant Breed 1999, 118(4):323-326.

54. Suwabe K, Iketani H, Nunome T, Kage T, Hirai M: Isolation and characterization of microsatellites in Brassica rapa L. Theor Appl Genet 2002, 104(6-7):1092-1098.

55. Lowe AJ, Jones AE, Raybould AF, Trick M, Moule CL, Edwards KJ: Transferability and genome specificity of a new set of microsatellite primers among Brassica species of the U triangle. Mol Ecol Notes 2002, 2(1):7-11.

56. Lowe AJ, Moule C, Trick M, Edwards KJ: Efficient large-scale development of microsatellites for marker and mapping applications in Brassica crop species. Theor App/ Genet 2004, 108(6):1103-1112. 
57. Piquemal J, Cinquin E, Couton F, Rondeau C, Seignoret E, Doucet I, Perret $\mathrm{D}$, Villeger MJ, Vincourt P, Blanchard P: Construction of an oilseed rape (Brassica napus L.) genetic map with SSR markers. Theor Appl Genet 2005, 111(8):1514-1523.

58. Choi SR, Teakle GR, Plaha P, Kim JH, Allender CJ, Beynon E, Piao ZY, Soengas P, Han TH, King GJ, Barker GC, Hand P, Lydiate DJ, Batley J, Edwards D, Koo DH, Bang JW, Park BS, Lim YP: The reference genetic linkage map for the multinational Brassica rapa genome sequencing project. Theor Appl Genet 2007, 115(6):777-792.

59. Cheng XM, Xu JS, Xia S, Gu JX, Yang Y, Fu J, Qian XJ, Zhang SC, Wu JS, Liu K: Development and genetic mapping of microsatellite markers from genome survey sequences in Brassica napus. Theor Appl Genet 2009, 118(6):1121-1131.

60. Sun M, Hua W, Liu J, Huang S, Wang X, Liu G, Wang H: Design of new genome- and gene-sourced primers and identification of QTL for seed oil content in a specially high-oil Brassica napus cultivar. Plos one 2012, 7(10):e47037.

61. Shi J, Huang S, Zhan J, Yu J, Wang X, Hua W, Liu S, Liu G, Wang H: Genome-wide microsatellite characterization and marker development in the sequenced Brassica crop species. DNA Res 2013, 21(1):53-68.

62. Kosambi DD: The estimation of map distances from recombination values. Ann Eugen 1944, 12(1):172-175.

63. Zeng ZB: Precision mapping of quantitative trait loci. Genetics 1994, 136(4):1457-1468.

64. Churchill GA, Doerge RW: Empirical threshold values for quantitative trait mapping. Genetics 1994, 138(3):963-971.

65. Long Y, Shi J, Qiu D, Li R, Zhang C, Wang J, Hou J, Zhao J, Shi L, Park BS, Choi SR, Lim YP, Meng J: Flowering time quantitative trait Loci analysis of oilseed brassica in multiple environments and genomewide alignment with Arabidopsis. Genetics 2007, 177(4):2433-2444.

66. Goffinet B, Gerber S: Quantitative trait loci: a meta-analysis. Genetics 2000, 155(1):463-473.

67. Arcade A, Labourdette A, Falque M, Mangin B, Chardon F, Charcosset A, Joets J: BioMercator: integrating genetic maps and QTL towards discovery of candidate genes. Bioinformatics 2004, 20(14):2324-2326.

68. Zhu J: Analysis of conditional genetic effects and variance components in developmental genetics. Genetics 1995, 141(4):1633-1639.

69. Wen W, Mei H, Feng F, Yu S, Huang Z, Wu J, Chen L, Xu X, Luo L: Population structure and association mapping on chromosome 7 using a diverse panel of Chinese germplasm of rice (Oryza sativa L.). Theor Appl Genet 2009, 119(3):459-470.

70. Breseghello F, Sorrells ME: Association mapping of kernel size and milling quality in wheat (Triticum aestivum L.) cultivars. Genetics 2006, 172(2):1165-1177.

71. Mather KA, Caicedo AL, Polato NR, Olsen KM, McCouch S, Purugganan MD: The extent of linkage disequilibrium in rice (Oryza sativa L.). Genetics 2007, 177(4):2223-2232.

72. Chen S, Nelson MN, Ghamkhar K, Fu T, Cowling WA: Divergent patterns of allelic diversity from similar origins: the case of oilseed rape (Brassica napus L.) in China and Australia. Genome 2008, 51(1):1-10.

73. Pritchard JK, Stephens M, Donnelly P: Inference of population structure using multilocus genotype data. Genetics 2000, 155(2):945-959.

74. Whitt SR, Buckler ES: Using natural allelic diversity to evaluate gene function. Methods Mol Biol 2003, 236:123-140.

75. Bradbury PJ, Zhang Z, Kroon DE, Casstevens TM, Ramdoss Y, Buckler ES: TASSEL: software for association mapping of complex traits in diverse samples. Bioinformatics 2007, 23(19):2633-2635.

76. Yu JM, Pressoir G, Briggs WH, Bi IV, Yamasaki M, Doebley JF, McMullen MD, Gaut BS, Nielsen DM, Holland JB, Kresovich S, Buckler ES: A unified mixedmodel method for association mapping that accounts for multiple levels of relatedness. Nat Genet 2006, 38(2):203-208.

doi:10.1186/1471-2229-14-114

Cite this article as: Li et al:: A combined linkage and regional association mapping validation and fine mapping of two major pleiotropic QTLs for seed weight and silique length in rapeseed (Brassica napus L.). BMC Plant Biology 2014 14:114.

\section{Submit your next manuscript to BioMed Central and take full advantage of:}

- Convenient online submission

- Thorough peer review

- No space constraints or color figure charges

- Immediate publication on acceptance

- Inclusion in PubMed, CAS, Scopus and Google Scholar

- Research which is freely available for redistribution 